\title{
Production of Metallic Iron from the Pudo Magnetite Ore using End-of-Life Rubber Tyre as Reductant: The Role of an Underlying Ankerite Ore as a Fluxing Agent on Productivity*
}

\author{
${ }^{1}$ E. Abotar, ${ }^{2}$ J. B. Dankwah, ${ }^{3}$ P. Koshy and ${ }^{1}$ J. R. Dankwah \\ ${ }^{1}$ University of Mines and Technology, Tarkwa, Ghana \\ ${ }^{2}$ University of South Australia, Adelaide, Australia \\ ${ }^{3}$ University of New South Wales, Sydney, Australia
}

Abotar, E., Dankwah, J. B., Koshy, P. and Dankwah, J. R. (2020), "Production of Metallic Iron from the Pudo Magnetite Ore using End-of-Life Rubber Tyre as Reductant: The Role of an Underlying Ankerite Ore as a Fluxing Agent on Productivity", Ghana Mining Journal, Vol. 20, No. 2, pp. 36-42.

\begin{abstract}
This research work investigated the nature of a nonmagnetic ore from Pudo in the Upper West Region of Ghana and its fluxing effect on the extent of reduction of the Pudo titaniferous magnetite ore using pulverised samples of charred carbonaceous materials generated from end-of-life vehicle tyres (ELT) as reductants. Reduction studies were conducted on composite pellets of the Pudo titaniferous magnetite iron ore containing fixed amounts of charred ELT and varying amounts $(0 \%, 10 \%, 15 \%, 20 \%, 30 \%, 40 \%$ and $50 \%)$ of the nonmagnetic fluxing material in a domestic microwave oven and the extent of reduction was calculated after microwave irradiation for 40 minutes. Analyses by XRF and SEM/EDS of the nonmagnetic ore revealed an Ankerite type of ore of the form $\mathrm{Ca}_{0.95} \mathrm{Fe}_{0.95} \mathrm{Mn}_{0.1}\left(\mathrm{CO}_{3}\right)_{2}$. From the microwave reduction studies it was observed that premium grade metallic iron could be produced from appropriate blends of the Pudo iron ores using ELT as reductant, with a measured extent of reduction up to $103.8 \%$. Further, the extent of reduction was observed to increase with an increase in the amount of the nonmagnetic fluxing material (Ankerite) that was added as fluxing agent.
\end{abstract}

Keywords: Ankerite, End-of-life Rubber Tyres, Fluxing Agent, Extent of Reduction

\section{Introduction}

The growing demand for automobiles and secondhand tyres has generated huge amounts of End-ofLife-Tyres (ELTs) in Ghana. In Ghana, unlike developed countries, ELTs are principally disposed in landfills or incinerated with little recycling approaches. Stockpiles of ELTs serve as ideal breeding grounds for mosquitoes and hiding places for reptiles such as snakes. This poses a significant health risk; fatal diseases such as malaria have been linked to such breeding grounds.

Moreover, stockpiles of these tyres can catch fire through lightning strikes or arson and such fires are notoriously difficult and costly to extinguish. Globally, about 1.5 billion ELTs make their way into the environmental cycle each year (Parthasarathy et al., 2016).

The Pudo iron ore is one of the major iron deposits in Ghana. The ore is in the form of titaniferrous magnetiferrous ore, containing both magnetite and titanium and a nonmagnetic type depending on its location (Kesse and Banson, 1975). The magnetite deposit has iron oxide $\left(\mathrm{Fe}_{2} \mathrm{O}_{3}\right)$ content of about 80 wt\%. Chemical analyses by Kesse and Banson (1975) revealed the absence of phosphorus and an extremely low sulphur content.

Work done by Dankwah et al., 2016 revealed that the nonmagnetic ore has an extremely low-grade iron ore with a very high silica content and moderately high alumina content. Although the iron oxide content is very low, the ore is self-fluxing as evidenced by its high $\mathrm{MgO}$ and $\mathrm{CaO}$ contents. Besides, it has no sulphur and its phosphorus content is negligible; these features make the Pudo iron deposit a promising source of iron oxide for the production of metallic iron for the steelmaking industry in Ghana.

However, there are no known coal deposits in Ghana. It will be expensive to import coals or metallurgical coke for an Iron making industry in Ghana. The use of postconsumer plastics as reductants or as a source of energy is currently gaining the attention of various researchers in the metallurgical industry (Matsuda et al., 2006; Nishioka et al., 2007; Matsuda et al., 2008; Ueki et al., 2008; Dankwah et al., 2011; Kongkarat et al., 2011; Murakami et al., 2009; Murakami and Kasai, 2011; Dankwah et al., 2012; Dankwah et al., 2013; Dankwah and Koshy, 2014; Dankwah et al., 2015a; Dankwah et al., 2015b). For thermosetting polymers and elastomers, Dankwah et al., 2012, Mansuri et al., 2013, Rajarao et al., 2014a, Rajarao et al., 2014b, Nath et al., 2012, Dhunna et al., 2014 and Dankwah and Baawuah, 2015 have used end-of-life rubber tyres, waste compact discs, end-of-life melamine and waste bakelite as reductants or for carbon dissolution studies. 
More information is needed in the literature on the use of ELTs as reductants for the production of metallic iron from naturally occurring iron ores.

In this present work the potential for producing metallic iron from Pudo Magnetite ore using ELTs as a reducing agent and ankerite as a fluxing gent is investigated.

\section{Resources and Methods Used}

\subsection{Materials}

ELT(s) were collected from a tyre waste dump opposite the main gate of the University of Mines and Technology (UMaT), Tarkwa.

ELT(s) were cut into smaller sizes, washed, and dried. Dried samples were charred in a gas fired furnace for $20 \mathrm{~min}$. The charred ELT(s) were pulverised using a standard laboratory ball mill to produce fine powders $(-125 \mu \mathrm{m})$ of carbonaceous materials as shown in Fig 1.

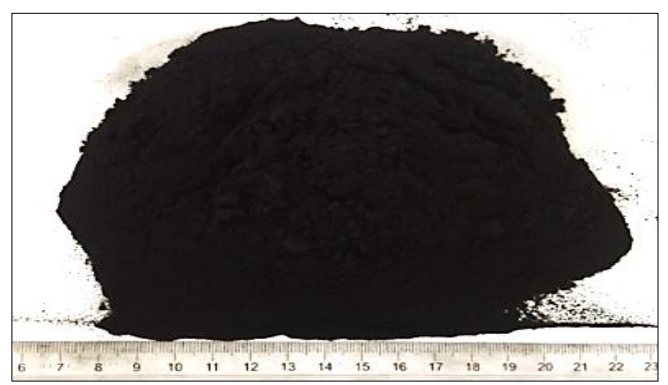

Fig. 1 Pulverised Sample of Charred ELT

Two iron ores (titaniferous magnetite and nonmagnetic) (Fig. 2) were obtained from Pudo in the Upper West Region of Ghana.

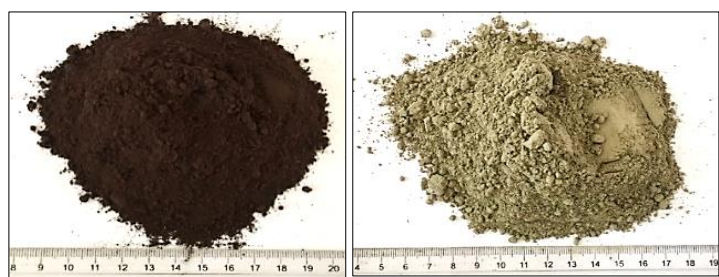

Fig. 2 (a) Pulverised Pudo Titaniferous Magnetite Iron Ore (b) Nonmagnetic Ankerite Ore

\subsection{Methods}

\subsubsection{Proximate Analysis of ELT(s)}

Analysis for moisture, volatile matter, ash and fixed carbon contents were carried out on samples of the shredded ELT(s) using the ASTM D-7582-15.

\subsubsection{Reduction Studies}

Spherical pellets were formed from pulverised iron oxide and charred ELT with a composition of $70 \%$ iron oxide (both magnetic and nonmagnetic), $28 \%$ of carbonaceous material and $2 \mathrm{wt} \%$ flour as binder and appropriate amount of water.

The blend composition for the iron ores is shown in Fig. 3

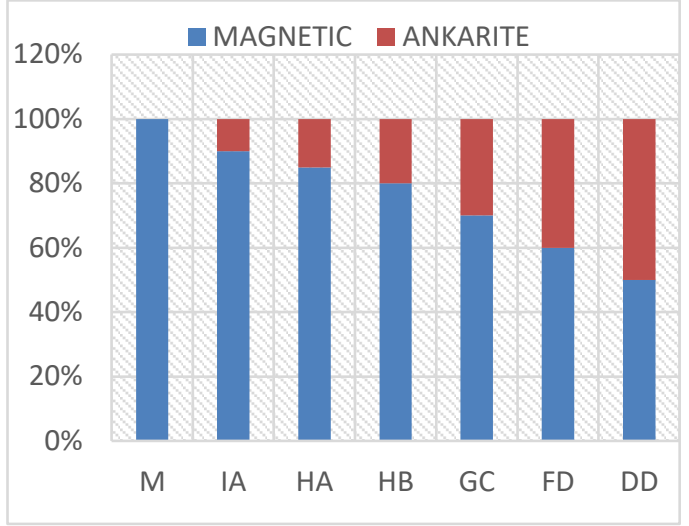

Fig. 3 Blend Ratio of the Pudo Magnetic and Ankerite ores used in the Reducibility Studies

After curing and drying for 96 hours the composite pellets were weighed using an electronic balance. The cured pellets were placed in a fireclay crucible and the crucible-pellet assembly was placed at the central position of a $2400 \mathrm{MW}, 50 \mathrm{~Hz}$, PIONEER domestic microwave oven as shown in Fig. 4. The composite pellets were irradiated for $40 \mathrm{~min}$, after which the crucible was taken out and quenched in air to stop any further reactions. The weights of the reduced iron pellets were then recorded using an electronic balance.

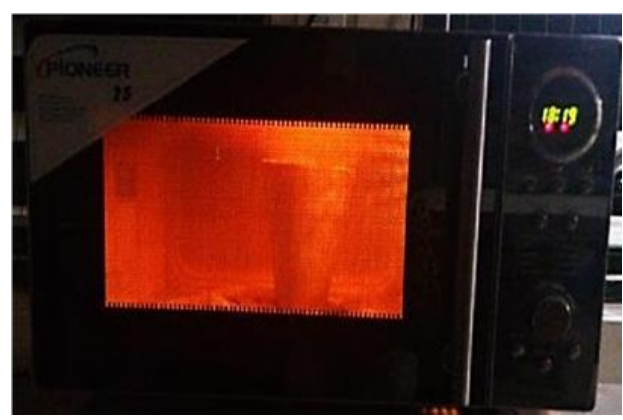

Fig. 4 Reduction Process in a Domestic Microwave Oven 


\section{Results and Discussion}

\subsection{Proximate Analyses of ELTs}

The result of proximate analyses (ASTM D-7582$15)$ of the ELT(s) particles is revealed in Table 1. The volatile matter was the highest composition, which was recorded as $61.67 \%$ followed by fixed carbon recorded as $29.88 \%$. The moisture and ash contents were noted as 0.85 and $7.60 \%$ respectively. These values confirm studies done by various researchers on the proximate analysis of ELT(s) as shown in Table 1. The fixed carbon content of the ELT(s) is an indication that End-of-Life Rubber Tyres could be transformed into valuable substance, carbon black for carbothermal reduction processes.

Table 1 Proximate Analysis of ELTs

\begin{tabular}{|l|c|c|c|c|}
\hline \multirow{2}{*}{ Author } & \multicolumn{4}{|c|}{ Component (wt \%) } \\
\cline { 2 - 5 } & Volatile & $\begin{array}{c}\text { Fixed } \\
\text { Carbon }\end{array}$ & Moisture & Ash \\
\hline $\begin{array}{l}\text { This } \\
\text { Research }\end{array}$ & $\mathbf{6 1 . 6 7}$ & $\mathbf{2 9 . 8 8}$ & $\mathbf{0 . 8 5}$ & $\mathbf{7 . 6}$ \\
\hline $\begin{array}{l}\text { Juma et al., } \\
(2006)\end{array}$ & 61.61 & 22.66 & 1.72 & 14.01 \\
\hline $\begin{array}{l}\text { Rodrigues et } \\
\text { al., (2001) }\end{array}$ & 58.8 & 27.7 & - & 3.9 \\
\hline $\begin{array}{l}\text { Lee et al., } \\
(1995)\end{array}$ & 67.3 & 28.5 & 0.5 & 3.7 \\
\hline $\begin{array}{l}\text { Chang } \text { et al., } \\
(1996)\end{array}$ & 62.32 & 26.26 & 1.31 & 10.29 \\
\hline $\begin{array}{l}\text { Gonzales et } \\
\text { al., (2001) }\end{array}$ & 61.9 & 29.2 & 0.7 & 8.0 \\
\hline
\end{tabular}

\subsection{Nature of the Pudo Iron Ores}

The chemical composition (wt\%) of the iron ores (determined by XRF analyses) at the Analytical Centre, UNSW, Australia is given in Table 2. From Table 2 it is seen that although the nonmagnetic ore has a very low iron oxide content, it is a self-fluxing ore owing to the presence of significant amounts of $\mathrm{MgO}, \mathrm{CaO}$ and $\mathrm{SiO}_{2}$. The magnetic ore on the other hand has a very high iron oxide content with virtually no sulphur and phosphorus. This makes it a suitable candidate for metallic iron production.

The SEM/EDS analyses of the Pudo iron ores (magnetic and nonmagnetic) before reduction are illustrated in Figs. 4 and 5 and Table 3 and 4, respectively. These show the point-by-point surface analyses of the magnetite and nonmagnetic ore. It is apparent from Table 4 that the Pudo nonmagnetic ore consists of $\mathrm{Ca}, \mathrm{Fe}, \mathrm{Mn}, \mathrm{C}$, and $\mathrm{O}$. From the atomic composition, the Pudo nonmagnetic ore can be represented by $\mathrm{Ca}_{0.95} \mathrm{Fe}_{0.95} \mathrm{Mn}_{0.1}\left(\mathrm{CO}_{3}\right)_{2}$, implying an ankerite form of ore.
Table 2 Chemical Composition (by XRF) of the Pudo Iron Ores used

\begin{tabular}{|l|c|c|}
\hline \multirow{2}{*}{ Component } & \multicolumn{2}{|c|}{ Composition (wt \%) } \\
\cline { 2 - 3 } & (Nonmagnetic) & Magnetic \\
\hline $\mathrm{Na}_{2} \mathrm{O}$ & 1.411 & 0.200 \\
\hline $\mathrm{MgO}$ & 9.057 & 1.679 \\
\hline $\mathrm{Al}_{2} \mathrm{O}_{3}$ & 11.844 & 3.864 \\
\hline $\mathrm{SiO}_{2}$ & 47.244 & 2.519 \\
\hline $\mathrm{P}_{2} \mathrm{O}_{5}$ & 0.010 & 0.010 \\
\hline $\mathrm{SO}_{3}$ & 0.000 & 0.018 \\
\hline $\mathrm{K}_{2} \mathrm{O}$ & 0.107 & 0.007 \\
\hline $\mathrm{CaO}^{2}$ & 12.048 & 0.068 \\
\hline $\mathrm{TiO}_{2}$ & 0.947 & 10.140 \\
\hline $\mathrm{Mn}_{3} \mathrm{O}_{4}$ & 0.456 & 0.409 \\
\hline $\mathrm{Fe}_{2} \mathrm{O}_{3}$ & 14.958 & 80.918 \\
\hline $\mathrm{LOI}^{2 O}$ & 1.96 & 1.16 \\
\hline
\end{tabular}
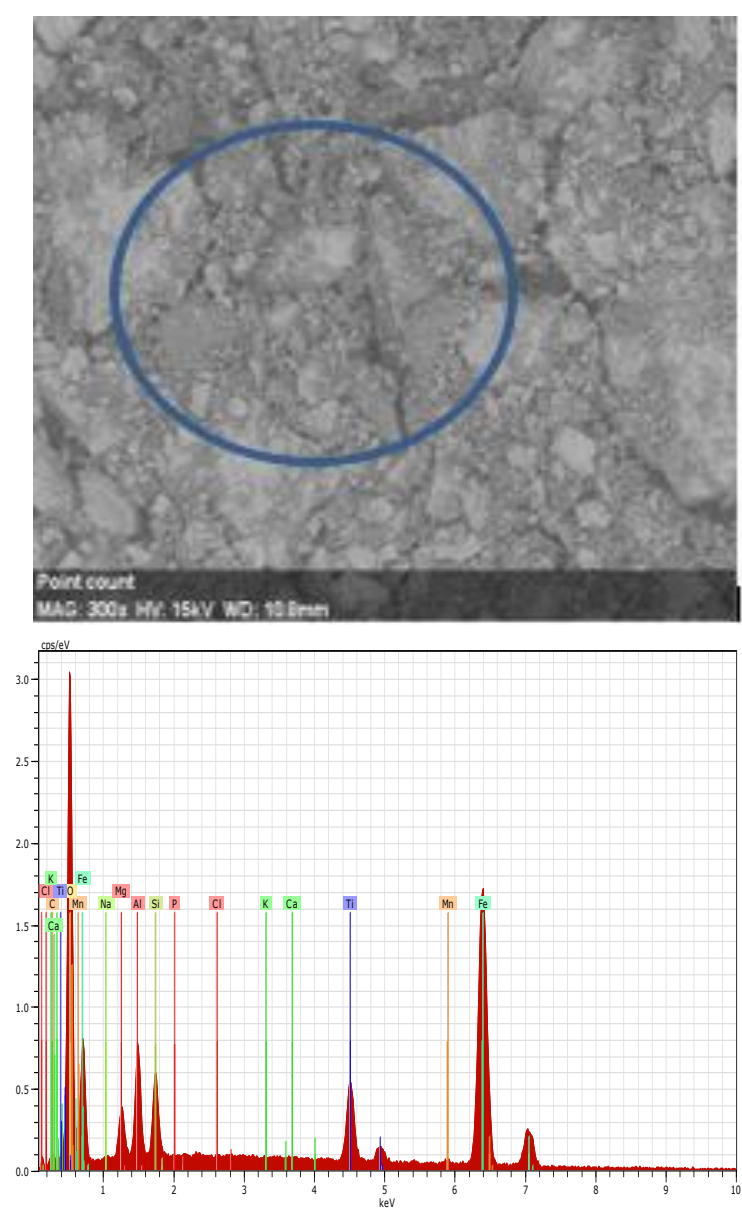

Fig. 4 SEM/EDs Analysis for Pudo Titaniferous Magnetic Iron Ore 
Table 3 Values of SEM/EDs Analysis for Pudo Titaniferous Magnetic Iron Ore

\begin{tabular}{lcc}
\hline Element (K-Series) & Weight \% & Atomic \% \\
\hline $\mathrm{Fe}$ & 49.2 & 24.25 \\
$\mathrm{O}$ & 32.03 & 55.1 \\
$\mathrm{Ti}$ & 5.62 & 3.23 \\
$\mathrm{Al}$ & 4.15 & 4.23 \\
$\mathrm{C}$ & 3.13 & 7.18 \\
$\mathrm{Si}$ & 2.76 & 2.7 \\
$\mathrm{Mg}$ & 2.38 & 2.7 \\
$\mathrm{Mn}$ & 0.32 & 0.16 \\
$\mathrm{Na}$ & 0.31 & 0.37 \\
$\mathrm{Ca}$ & 0.1 & 0.07 \\
\hline Sum & $\mathbf{1 0 0}$ & $\mathbf{1 0 0 . 0}$ \\
\hline
\end{tabular}
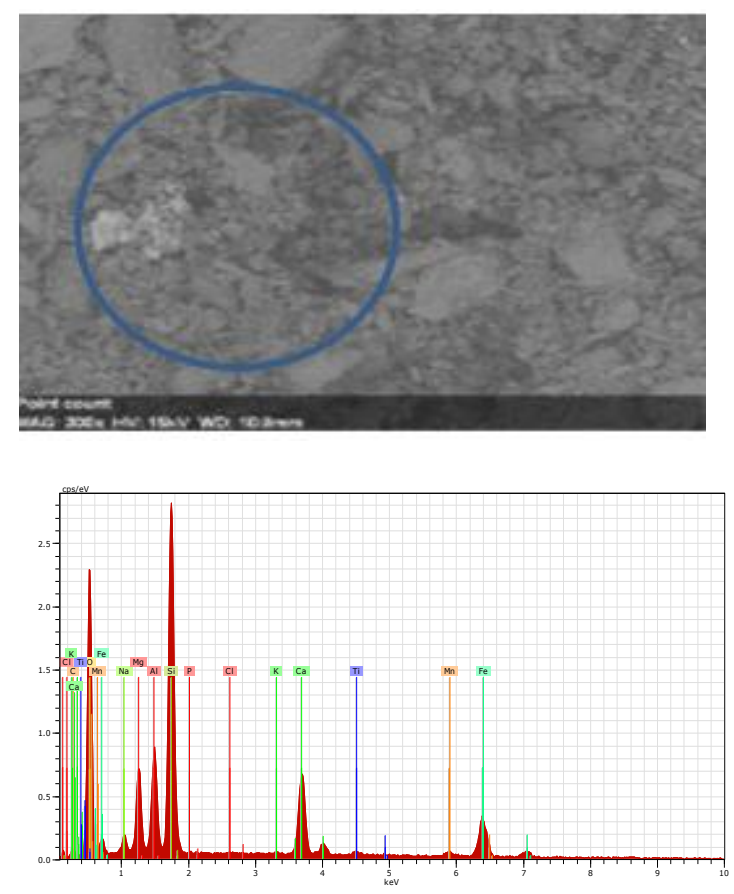

Fig. 5 SEM/EDs Analysis for Pudo NonMagnetic Iron Ore

Table 4 Values of SEM/EDS Analysis for Ankerite Ore

\begin{tabular}{lcc}
\hline Element (K-Series) & Weight \% & Atomic \% \\
\hline $\mathrm{Fe}$ & 10.17 & 3.86 \\
$\mathrm{O}$ & 43.51 & 57.64 \\
$\mathrm{Si}$ & 20.08 & 15.15 \\
$\mathrm{Ca}$ & 7.30 & 3.86 \\
$\mathrm{Al}$ & 5.91 & 4.65 \\
$\mathrm{Mg}$ & 5.28 & 4.60 \\
$\mathrm{C}$ & 4.60 & 8.13 \\
$\mathrm{Na}$ & 1.56 & 1.44 \\
$\mathrm{Mn}$ & 1.02 & 0.39 \\
$\mathrm{Ti}$ & 0.35 & 0.15 \\
$\mathrm{P}$ & 0.01 & 0.01 \\
\hline Sum & $\mathbf{1 0 0}$ & $\mathbf{1 0 0}$ \\
\hline
\end{tabular}

Grades of Iron ore are classified according to their Fe content. An iron ore is said to be of high grade when its $\mathrm{Fe}$ content is more than $65 \mathrm{wt} . \%$, low grade when its $\mathrm{Fe}$ content is less than 58 wt.\%, and medium grade when its $\mathrm{Fe}$ content is between 58 wt.\% and 64 wt.\% (Kiptarus et. al. 2015; Muwanguzi et. al. 2012).

The potential for worldwide commercial exploitation of the Pudo iron ores is low but it is possible to exploit it on small scale basis. Comparing these values to the world's iron ore classification in Table 5 the Pudo magnetic iron ore corresponds to the low-grade iron ore (approximately $57 \mathrm{wt} . \%$ which is less than $58 \mathrm{wt} . \%$ ).

Table 5 Generalized Percentage Classification of Iron Ores

\begin{tabular}{|l|c|c|c|}
\hline \multirow{2}{*}{ Components } & \multicolumn{3}{|c|}{ Total Iron Content } \\
\cline { 2 - 4 } & Low & Medium & High \\
\hline Content Mass \% & $<58$ & $62-64$ & $>65$ \\
\hline
\end{tabular}

(Source: Kiptarus et. al. 2015)

\subsection{Effect of Ankerite Addition on the Extent of Reduction}

Fig. 6 shows the variation of extent of reduction with the content of ankerite in the pellet. The extent of reduction for the magnetic ore was $81.70 \%$. The extent of reduction ranged a little over $87 \%$ to $103 \%$ for the various blends of the magnetic and ankerite ores.

The extent of reduction for the various blends increased with an increase in content of the nonmagnetic ore in the composite pellet. This is because of the self-fluxing ability of the ankerite as explained earlier. $\mathrm{CaO}$ fluxes the gangue in the iron ore to form a silicate melt phase. $\mathrm{MgO}$ either enters the magnetite lattice to form magnesio ferrite or dissolves in the slag phase. These melting phases interact with each other and dissolve a variable amount of iron oxides.

The observed extent of reduction in excess of $100 \%$ is attributed to the simultaneous reduction of $\mathrm{SiO}_{2}$ and the blend of the magnetite and non-magnetic ore to form an alloy of ferrosilicon. 


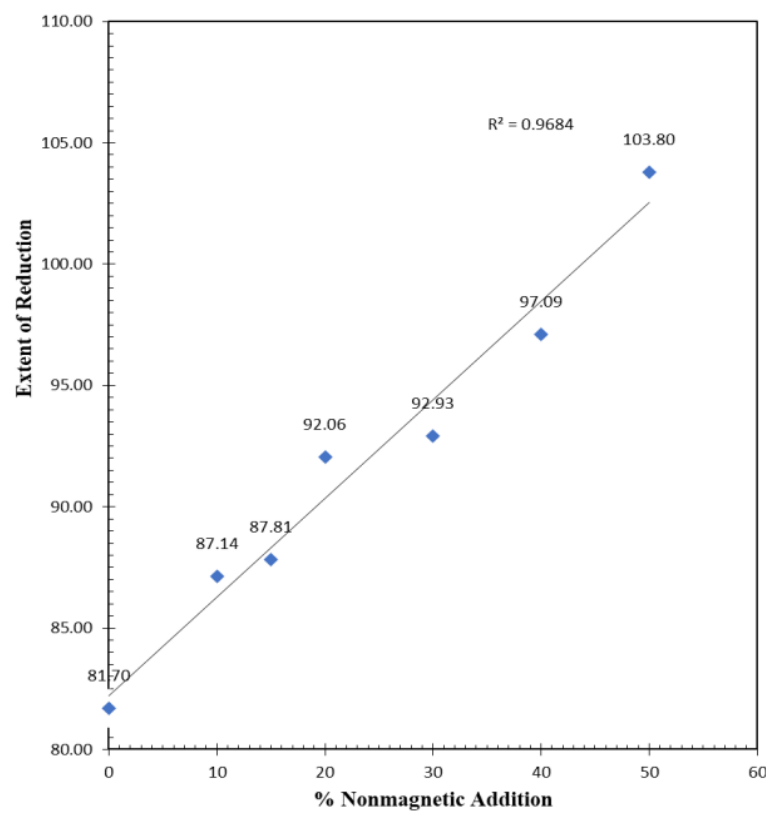

Fig. 6 Graph of Extent of Reduction for the Magnetite and Various Blends of the Magnetite and Nonmagnetic Ores

\subsection{Effect of Ankerite on the Nature of Metals Produced}

It is observed from Fig. 7 below that direct reduced iron was produced. It has an irregular sponge-like structure. The reduced metal was formed in the solid state. The metallised portion of the DRI did not melt. This reduced pellet was the $100 \%$ magnetite-ELT composite pellet. It has a low metallisation because magnetite ores are naturally difficult to reduce to metallic iron because of its low porosity. Moreover, the Pudo magnetite ore is not a self-fluxing ore to enter into the molten state during reduction.

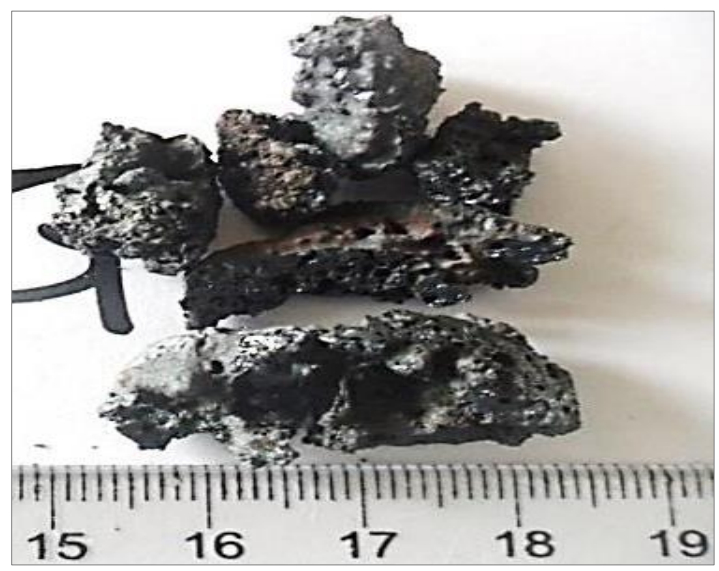

Fig. 7 Samples of Reduced Material obtained after Reduction of $\mathbf{1 0 0 \%}$ Pudo Magnetic Ore with ELT
Fig. 8 illustrates the effect of $15 \%$ ankerite addition on the nature of metal produced from the Pudo magnetic ore.

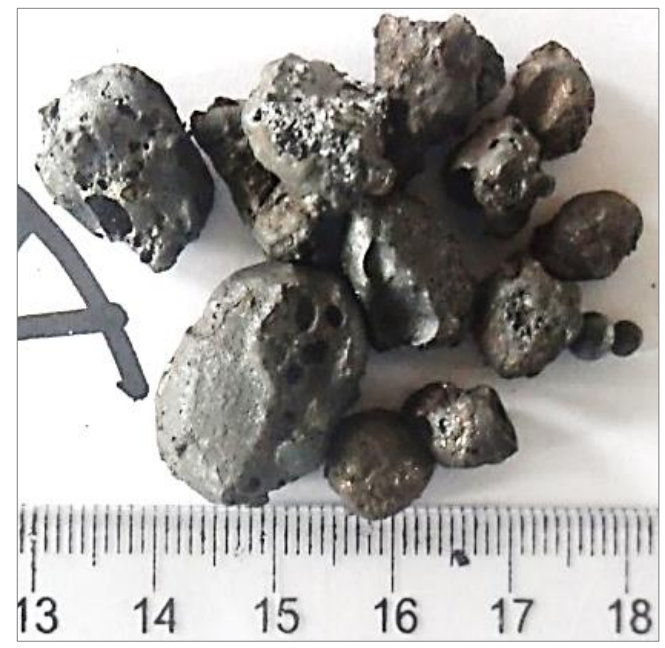

Fig. 8 Samples of Reduced Metal obtained after Reduction of Maximum Blend of $15 \%$ Ankerite Ore

It can be observed from Fig. 8 above that blends with a maximum of $15 \%$ ankerite had irregular to spherical shape. They have higher metallisation than DRI due to the partial slag separation and reduced number of pores. This is because the ankerite ore served as a fluxing agent. Transition Direct Reduced Iron (TDRI) was produced as more carbon dissolved in DRI and the metallised portion partially melted as a result of the addition of the ankerite ore which served as flux.

Fig. 9 illustrates the nature of metal produced when the content of ankerite increased above $15 \%$. the metals produced were spherical in nature. These spheres of metal were embedded in the slag phase of the reduced material and were subjected to breakage to free the spherical metals. Slag separation was achieved due to the formation of two liquid products; slag and metal. This is due to the immiscibility and density difference. The spherical shape of the metallic iron nuggets is an indication that they were solidified from the molten state. Physical separation of the mixture of reduced metals and slag components was effected using a low intensity handheld magnet. The spherical nature of the reduced metal could be attributed to the high $\mathrm{CaO}$ and $\mathrm{MgO}$ in the ankerite and the excess carbon present in the iron ore-carbon composite causing the reduced iron to pick up these excess carbons. This causes the reduced iron to melt at a lower temperature into a molten mass that solidifies into spherical nuggets when the microwave power is put off. 


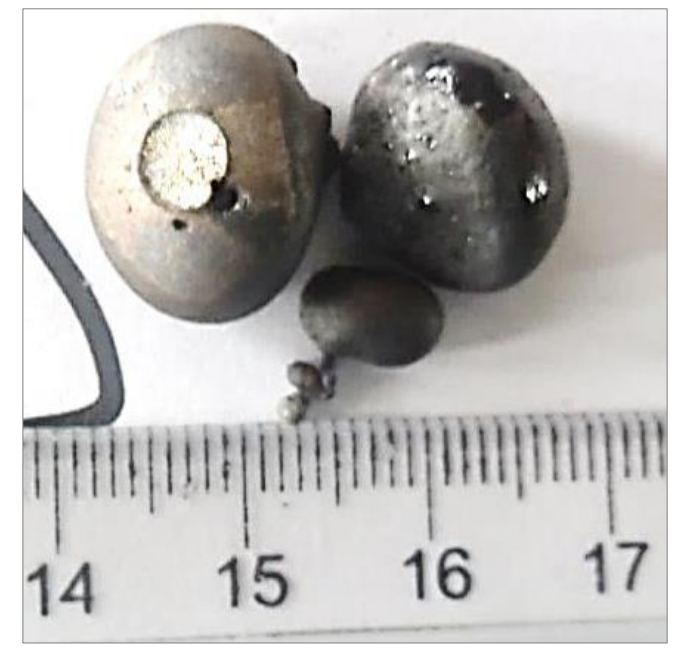

Fig. 9 Samples of Reduced Metal obtained after Reduction of Blend Consisting of $50 \%$ Ankerite Ore

\section{Conclusions}

A laboratory investigation has been conducted on the the nature of ankerite ore from Pudo and its fluxing effect on the extent of reduction of the Pudo titaniferous magnetite ore using pulverised samples of charred carbonaceous materials generated from end-of-life vehicle tyres (ELT) as reductants. Major findings of the investigation are:

(i) ELTs are excellent potential source of carbonaceous material for iron oxide reduction.

(ii) ELT utilised for this investigation has a fixed carbon content of $29.88 \%$ from its proximate analysis.

(iii) The Pudo nonmagnetic ore is an ankerite type of ore of the form $\mathrm{Ca}_{0.95} \mathrm{Fe}_{0.95} \mathrm{Mn}_{0.1}\left(\mathrm{CO}_{3}\right)_{2}$

(iv) The Extent of reduction for the $100 \%$ magnetite ore was $81.70 \%$; its metal had an irregular spongy-like structure.

(v) Addition of ankerite to the Pudo magnetic ore resulted in an improvement in the extent of reduction and the quality of metal produced.

\section{Acknowledgements}

Part of the analyses for the investigation was conducted at the School of Materials Science and Engineering and the Analytical Centre, School of Chemical Science and Engineering, UNSW, Sydney, Australia. The authors are grateful to the various authorising bodies for the assistance received.

\section{References}

Arion, A., Baronnet, F., Lartiges, S. and Birat, J. P. (2001), "Characterisation of Emissions during the Heating of Tyre Contaminated Scrap", Chemosphere, Vol. 42, No. 5-7, pp. 853-859.

Atal, A. and Levendis, Y. A. (1995), "Comparison of the Combustion Behaviour of Pulverized Waste Tyres and Coal", Fuel, Vol. 74, No. 11, pp. 1570-1581.

Babich, A., Senk, D., Gudenau, H. W., Mavrommatis, K. T. (2008), Ironmaking, Aachen University Department of Ferrous Metallurgy, Aachen, 204 pp.

Berrueco, C., Esperanza, E., Mastral, F. J., Ceamanos, J., and Garcia-Bacaicoa, P. (2005), "Pyrolysis of Waste Tyres in an Atmospheric Static-bed Batch Reactor: Analysis of the Gases obtained", J. Anal. Appl. Pyrolysis, Vol. 73, pp. 65-73.

Chang, Y. M. (1996), "Tyre Degradation Rate and Product Yields”, Resources, Conservation and Recycling, Vol. 17, No. 2, pp. 125-139.

Dankwah, J. R. (2018), "Laboratory Studies on the Effect of End-of-Life Rubber Tyre Blending with Metallurgical Coke on Slag Foaming in Electric Arc Furnace Steelmaking", Ghana Journal of Technology, Vol. 3, No. 1, pp. 48 -57.

Dankwah, J. R. and Buah, W.K. (2017), "Recycling Waste Polyurethane as Carbon Resource in Ironmaking ", Ghana Mining Journal, Vol. 17, No. 1, pp. $73-77$.

Dankwah, J. R., Abotar, E., Gordon, J. J. K, and Koshy, P. (2016a), "Recycling Waste Electrical Socket as a Carbon Resource in Ironmaking", Ghana Mining Journal, Vol. 16, No. 1, pp. $76-$ 82.

Dankwah, J. R., Aakyiir, M. N. and Koshy, P, (2016b) "Microwave Production of Iron Nuggets from the Pudo Iron Ore using Charred "Pito" Waste as Reductant", $4^{\text {th }}$ UMaT Biennial International Mining and Mineral Conference, pp. MR 93-99.

Dankwah, J. R., Amoah, T., Dankwah, J., and Fosu, A. Y. (2015), "Recycling Mixed Plastics Waste as Reductant in Ironmaking", Ghana Mining Journal, Vol. 15, No. 2, pp. $73-80$.

Dankwah, J.R. (2014), "Reduction of FeO in EAF Steelmaking Slag by End-of-Life Polystyrene and It's Blend with Metallurgical Coke", Int. Journal of Engineering Research and Applications, Vol. 4, Issue 1 (Version 3), pp. 274-279.

Dankwah, J. R., Koshy, P., O'Kane, P. and Sahajwalla, V. (2012), "Reduction of $\mathrm{FeO}$ in EAF Steelmaking Slag by Blends of Metallurgical Coke and End-of-Life Tyres", Steel Research International, Vol. 83, No.8, pp. 766-774. 
Dutta, S.K., and Sah, R. (2016), "Direct Reduced Iron: Production", In Encyclopaedia of Iron, Steel, and Their Alloys, Taylor and Francis: New York, Published online: 30 Mar 2016, pp. 10821108.

Fruehan, R. J. (1977), "The Rate of Reduction of Iron Oxides by Carbon", Metallurgical Transactions B, Vol. 8, No.1, pp 279-286.

Hayashi, M., Takeda, K., Kashimura, K., Watanabe, T. And Nagata, K., (2013), "Carbothermic Reduction of Hematite Powders by Microwave Heating”, ISIJ International, Vol. 53, No. 7, pp. 1125-1130.

Kesse, G. O. and Banson, J. K. A. (1975), "Iron Ore Deposits of Ghana", Ghana Geological Survey Report, No. 7, 55 pp.

Kiptarus, J. J., Muumbo, A. M., Makokha, A. B., Kimutai, S. K. (2015), "Characterization of Selected Mineral Ores in the Eastern Zone of Kenya: Case Study of Mwingi North Constituency in Kitui County", International Journal of Mining Engineering and Mineral Processing, vol. 4, No. 1, pp. 8-17.

Mansuri, I. A., Khanna, R., Rajarao, R. and Sahajwalla, V., (2013), "Recycling Waste CDs as Carbon Resource: Dissolution of Carbon into Molten Iron at $1550{ }^{\circ} \mathrm{C}$ ", ISIJ International, Vol. 53, No. 12, pp. 2259-2265.

Menéndez, J.A., Arenillas, A., Fidalgo, B., Fernández, Y., Zubizarreta, L., Calvo, E.G. and Bermúdez, J.M. (2010), "Microwave Heating Processes Involving Carbon Materials", Fuel Processing Technology, 91 (1), pp. 1-8.

Murakami, T. and Kasai, E. (2011), "Reduction Mechanism of Iron Oxide-carbon Composite with Polyethylene at Lower Temperature ", ISIJ Int., 51(1), pp. 9-13.

Murakami, T., Akiyama, T. and Kasai, E., (2009), "Reduction Behaviour of Hematite Composite containing Polyethylene and Graphite with Different Structures with Increasing Temperature", ISIJ Int., 49(6), pp. 809-814.

Muwanguzi, A.J.B., Karasev, A.V., Byaruhanga, J.K. and Jönsson, P.G. (2012), "Characterization of Chemical Composition and Microstructure of Natural Iron Ore from Muko Deposits", International Scholarly Research Network, ISRN Materials Science Volume 2012, Article ID 174803, pp. 1-9.

Muwanguzi, A.J.B. (2010), "Characterisation of Muko Iron Ores (Uganda) for the Different Routes of Iron Production', Published Licentiate Thesis, Royal Institute of Technology, SE-100 44 Stockholm, Sweden, 27 pp.

Nishioka, K., Taniguchi, T., Ueki, Y., Ohno, K., Maeda, T. And Shimizu, M., (2007), "Gasification and Reduction Behaviour of Plastics and Iron Ore Mixtures by Microwave Heating", ISIJ International, Vol. 47, No. 4, pp. 602-607.
Sahajwalla, V., Zaharia M., Rahman, M., Khanna, R., Saha-Chaudhury, N., O'Kane, P., Dicker, J., Skidmore, C. and Knights, D. (2011), "Recycling Rubber Tyres and Waste Plastics in EAF Steelmaking" Journal of Steel Research Int. Vol. 82, No. 5, pp. 565-572.

Ueki, Y., Ohno, K., Maeda, T., Nishioka, K. and Shimizu, M. (2008), "Reaction Behaviour during Heating Waste Plastic Materials and Iron Oxide Composites", ISIJ Int., Vol. 48, pp. 1670 - 1675. Wadhwa, A. (2016), "Energy Recovery from endof-life tyres through an alternative to thermochemical process: A short review", International Journal of Sustainable Energy and Environment, Vol. 4, No. 3, pp. 1-3.

\section{Authors}

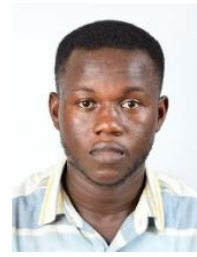

Emmanuel Abotar is an Assistant Lecturer and a PhD candidate at the Minerals Engineering Department of the University of Mines and Technology, (UMaT), Tarkwa. He obtained his MPhil and BSc Degrees in Minerals Engineering at the University of Mines and Technology. His current research areas include Mineral processing, iron and steelmaking, high-temperature metallurgical processes and utilisation of waste polymers in metal extraction processes.

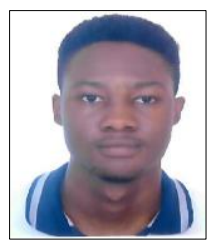

James B. Dankwah is a $\mathrm{PhD}$ candidate at the Future Industries Institute of University of South Australia. He obtained his BSc Degree in Minerals Engineering at the University of Mines and Technology, Tarkwa, Ghana. His current project is the production of ferrosilicon alloys from the nonmagnetic portion of the Pudo iron ore using end-of-life plastics as reducing agents.

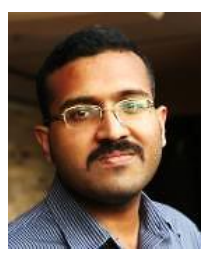

Pramod Koshy is currently a Senior Research Fellow at the School of Materials Science and Engineering, UNSW, Australia. He completed his Ph.D. from the School of Materials Science and Engineering, UNSW, Australia. His main areas of research include photocatalytic materials, high-temperature metal/ceramic interfaces, and utilization of waste materials.

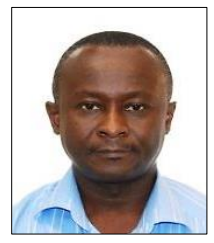

James R. Dankwah is an Associate Professor at the Minerals Engineering Dept. at the University of Mines and Technology, UMaT, Tarkwa. He obtained his PhD from the School of Materials Science and Engineering, UNSW, Australia, MSc (Process Metallurgy) from the Norwegian University of Science and Technology and BSc (Metallurgical Engineering) from the Kwame Nkrumah University of Science and Technology, Kumasi, Ghana. He is a Fellow of the West African Institute of Mining, Metallurgy and Petroleum (WAIMM). His current research areas include iron and steelmaking, high-temperature metallurgical processes, utilisation of waste polymers in metal extraction processes and recycling agricultural waste into building blocks materials for affordable housing for the rural folks. 